\title{
Dissociating predictability, plausibility and possibility of sentence continuations in reading: Evidence from late- positivity ERPs
}

\author{
Laura Quante $^{\text {Corresp., 1,2 }}$, Jens Bölte ${ }^{1,2}$, Pienie Zwitserlood ${ }^{1,2}$ \\ 1 Department of Psychology, University of Münster, Münster, Germany \\ 2 Otto-Creutzfeldt-Center for Cognitive and Behavioral Neuroscience, University of Münster, Münster, Germany \\ Corresponding Author: Laura Quante \\ Email address: I.quante@uni-muenster.de
}

Late positive ERP components occurring after the N400, traditionally linked to reanalysis due to syntactic incongruence, are increasingly considered to also reflect reanalysis and repair due to semantic difficulty. Semantic problems can have different origins, such as a mismatch of specific predictions based on the context, low plausibility, or even semantic impossibility of a word in the given context. DeLong, Quante, and Kutas (Neuropsychologia, 2014) provided the first direct evidence for topographically different late positivities for prediction mismatch (left frontal late positivity for plausible but unexpected words) and plausibility violation (posterior-parietal late positivity for implausible, incongruent words). The aim of the current study is twofold: (1) to replicate this dissociation of ERP effects for plausibility violations and prediction mismatch in a different language, and (2) to test an additional contrast within implausible words, comparing impossible and possible sentence continuations. Our results replicate DeLong et al. (2014) with different materials in a different language, showing graded effects for predictability and plausibility at the level of the N400, a dissociation of plausible and implausible, anomalous continuations in posterior late positivities and an effect of prediction mismatch on late positivities at left-frontal sites. In addition, we found some evidence for a dissociation, at these left-frontal sites, between implausible words that were fully incompatible with the preceding discourse and those for which an interpretation is possible. We discuss the theoretical impact of our results in the light of prediction, updating and integration of words into the discourse. 


\section{Dissociating predictability, plausibility and possibility of}

\section{sentence continuations in reading: Evidence from late-}

\section{positivity ERPs}

Laura Quantea,b, Jens Bölte ${ }^{\mathrm{a}, \mathrm{b}}$, Pienie Zwitserlood ${ }^{\mathrm{a}, \mathrm{b}}$

${ }^{a}$ Department of Psychology, University of Münster, Fliednerstraße 21, 48149 Münster, Germany

${ }^{\mathrm{b}}$ Otto-Creutzfeldt-Center for Cognitive and Behavioral Neuroscience, University of Münster, Fliednerstraße 21, 48149 Münster, Germany

Corresponding author:

Laura Quante

Email address: 1.quante@uni-muenster.de 


\section{Abstract}

3 due to syntactic incongruence, are increasingly considered to also reflect reanalysis and repair due

4 to semantic difficulty. Semantic problems can have different origins, such as a mismatch of

5 specific predictions based on the context, low plausibility, or even semantic impossibility of a

6 word in the given context. DeLong, Quante, and Kutas (Neuropsychologia, 2014) provided the

7 first direct evidence for topographically different late positivities for prediction mismatch (left

8 frontal late positivity for plausible but unexpected words) and plausibility violation (posterior-

9 parietal late positivity for implausible, incongruent words). The aim of the current study is twofold:

10 (1) to replicate this dissociation of ERP effects for plausibility violations and prediction mismatch

11 in a different language, and (2) to test an additional contrast within implausible words, comparing

12 impossible and possible sentence continuations. Our results replicate DeLong et al. (2014) with

13 different materials in a different language, showing graded effects for predictability and

14 plausibility at the level of the N400, a dissociation of plausible and implausible, anomalous

15 continuations in posterior late positivities and an effect of prediction mismatch on late positivities

16 at left-frontal sites. In addition, we found some evidence for a dissociation, at these left-frontal

17 sites, between implausible words that were fully incompatible with the preceding discourse and

18 those for which an interpretation is possible. We discuss the theoretical impact of our results in the

19 light of prediction, updating and integration of words into the discourse. 
The study of effects of context on language processing has a long tradition in

25

psycholinguistics, as modular (cf. Forster, 1981) and interactive (cf. McClelland \& Rumelhart, 1981; Marslen-Wilson, 1987) theories of word recognition drastically differed with respect to the role allotted to information stemming from sources other than the word itself. Proof for an impact of contextual, top-down information on word recognition was already provided more than 30 years ago, with priming paradigms and reaction time data (cf. Swinney, 1979; Schwaneflugel \& Shoben, 1985). The advent of event-related potentials again fired the debate, because they allow insights into the time-course of word recognition, which is difficult to come by with reaction times (but see Zwitserlood, 1989). Ever since, a wealth of studies has shown that contextual information, when constraining enough, has an early impact on lexical processing - even to the extent that upcoming words are anticipated (Kutas \& Federmeier, 2000; van Berkum, Zwitserlood, Hagoort, \& Brown, 2003; DeLong, Urbach, \& Kutas, 2005; van Berkum, Brown, Zwitserlood, \& Hagoort, 2005). It is thus not surprising that terminology has changed, and "anticipation" and "prediction" are now used to refer to the impact, on lexical processing, of knowledge from sources other than the current input (cf. Van Petten \& Luka, 2012; Huettig \& Janse, 2016; Kuperberg \& Jaeger, 2016). Whereas most researchers agree that (features of) upcoming words are predicted under certain circumstances, it remains unresolved which factors promote (or prevent) predictive processing, and what information about words (e.g., semantics, word forms) is predicted (see Ito et al., 2016; Kuperberg \& Jaeger, 2016).

To study effects of semantic context, expectation and prediction in language comprehension, a particular event-related potential (ERP) component, the N400 (Kutas \& Hillyard, 1980), has been used extensively. The N400 is a negative-going wave peaking around 
$46400 \mathrm{~ms}$ after stimulus onset, which is related to semantic processing (for a review, see Kutas \&

47 Federmeier, 2011). For example, its amplitude is negatively correlated to a word's cloze

48 probability (proportion of respondents who completed a given context with this particular word),

49 a measure of semantic expectancy. Words with strong contextual support show a decrease in N400

50 amplitude relative to words that are less predictable or do not fit the context (Kutas \& Federmeier,

51 2011). There is also evidence for ERP effects as a function of predictability in time windows

52 preceding the N400 (e.g., van Berkum, Zwitserlood, Hagoort, \& Brown, 2003; Dikker \&

53 Pylkkänen, 2011; Lau, Holcomb, \& Kuperberg, 2013; Brothers, Swaab, \& Traxler, 2015; see

54 Kuperberg \& Jaeger, 2016, for an overview). However, evidence for the actual pre-activation or

55 anticipation of upcoming words, assessed before any of their input becomes available, is less

56 abundant (but see DeLong, Urbach, and Kutas, 2005; van Berkum, Brown, Zwitserlood, Kooijman

57 \& Hagoort, 2005; Szewczyk \& Schriefers, 2013; Ito, Corley, Pickering, Martin, \& Nieuwland, 58 2016).

Our study uses ERPs and does not focus on prediction or expectation per se, but on the

60 consequences of prediction or expectation mismatch, and, more generally speaking, of contextual

61 mismatch. ${ }^{i}$ Van Petten and Luka (2012) proposed that if listeners and readers predict upcoming

62 words, the EEG signal should reflect not only benefits of a confirmed prediction (visible as

63 attenuation of the N400) but also costs of a disconfirmed prediction. In their review article, they

64 assessed studies that compared congruent sentence completions with semantically anomalous

65 completions, and often observed a late positivity, about 600-900 ms after critical-word onset, with

66 a mainly parietal scalp topography. In addition, an anterior positivity was sometimes observed

67 when ERPs for unexpected but semantically congruent sentence completions were compared to 
68 predictable, expected completions. It should be noted, however, that the $60+$ studies included

69 showed a great variability in the post-N400 time window.

70 It thus seems that unexpected continuations that allow construction of a possible overall 71 sentence meaning differ from anomalous completions. Interestingly, studies that manipulate 72 semantic expectancy have predominantly used anomalous or unexpected plausible completions, 73 but rarely both. This motivated DeLong, Quante, and Kutas (2014) to contrast different levels of 74 plausibility within the same study, to determine how predictability and plausibility each contribute 75 to word recognition. As completions of highly constraining sentence pairs (For the snowman's 76 eyes, the kids used two pieces of coal. For his nose, they used ....), DeLong et al. compared ERPs

77 to highly predicable, expected (a carrot), unexpected but somewhat plausible (a banana), and 78 unexpected, implausible, anomalous (a groan) words. The unexpected but plausible continuations should induce costs of disconfirmed prediction, combined with effort to integrate the unexpected noun - signaled by frontal late positivity. This does not hold for anomalous continuations that cannot be integrated with the current context. DeLong and colleagues observed a posterior late positivity to anomalous completions, and an anterior late positivity to unexpected but plausible completions, thus confirming Van Petten and Luka's (2012) conjecture. Corroboration for a particular function of the frontal late positivity, also labeled frontal PNP (post-N400 positivity), in prediction-related revision was recently provided by Swaab and colleagues (Boudewyn, Long, \& Swaab, 2015; Brothers, Swaab, \& Traxler, 2015). seems to affect late stages of processing, which is corroborated by eye-tracking studies (Staub, 89 2015, for an overview). Interestingly, Rayner, Warren, Juhasz, \& Liversedge et al. (2004) and Warren and McConnell (2007) further distinguished between plausibility and possibility, by 
91 comparing words that result in implausible but possible meaning for the full sentence, to words

92 that induce an impossible overall sentence meaning, because they violate selection restrictions

93 (e.g., "inflate a carrot") for example. In both studies, effects of words leading to either impossible

94 or implausible sentence meaning were dissociable in eye-movement measures.

Processing differences between implausible and impossible sentence overall meaning are

96 also visible in EEG data. For example, Paczynski and Kuperberg (2012) showed that selection-

97 restriction violations evoked a posterior positivity between 700 to $900 \mathrm{~ms}$ after critical word onset,

98 whereas violations of world knowledge, which result in implausible but still possible sentence

99 meaning, did not differ from plausible sentences in this time window. Similar results were shown

100 by Kuperberg, Sitnikova, Caplan, and Holcomb (2003), Geyer, Holcomb, Kuperberg, and

101 Perlmutter (2006), and Paczynski, Kreher, Ditman, Holcomb, and Kuperberg (2006). When

102 Kuperberg (2007) evaluated factors evoking a late positivity, she concluded that none of the

103 following factors - the presence of selection-restriction violations, semantic associations between

104 the critical word and the preceding context, specific task instructions, or constraining context - by

105 themselves could explain all results. One hypothesis that she advanced was that the impossibility

106 to establish an overall meaning for the sentence might be the crucial factor inducing a late positivity

107 on the critical word.

Given the variable nature of late positivities, and given the dire need for replication studies

109 of phenomena that are rather new or for which evidence is scarce (see Nieuwland et al., 2017; see

110 also Dennis \& Valacich, 2014), the present study aimed to replicate DeLong et al.'s (2014) second

111 experiment, with German stimuli presented to German native speakers. In addition, inspired by

112 suggestions made by Kuperberg (2007) and DeLong et al. (2014), we analyzed differences

113 between implausible word completions that resulted in either possible or impossible overall 
114 sentence meaning. To create a condition of impossible sentence meaning, we divided the materials

115 into impossible and possible sets by means of subjective possibility ratings, collected in a pretest.

116 Following DeLong et al. (2014), we predicted a graded effect of contextual fit of critical

117 words at the level of the N400, with implausible continuations showing enhanced negativity

118 relative to unexpected but plausible words. Next, we expect a predictability effect, showing as an

119 anterior late positivity - relative to expected nouns - to unexpected but plausible sentence

120 completions, but not to implausible nouns. Next, we predict a plausibility effect, with a posterior

121 positivity only for implausible, anomalous sentence completions. If Kuperberg's (2007)

122 assumption is correct, we predict this posterior late positivity only for those sentence completions

123 that are truly anomalous and lead to an impossible overall sentence meaning, but not for those that

124 allow an integration of the critical word with the preceding discourse, resulting in a perhaps

125 implausible but nevertheless possible real-world meaning. This would constitute an effect of

126 possibility, which also might show in a difference between possible and impossible implausible

127 continuations in late positivity at anterior sites, with the possible continuations coinciding with 128 plausible but unexpected ones.

\section{Material and Methods}

131

132

134

135

\subsection{Stimuli}

Stimuli were 150 constraining German sentence pairs (mean contextual constraint $=0.77$, $\mathrm{SD}=0.14$, see cloze probability norming described below), which led to expectations for particular sentence-medial words. Following the condition labels used in DeLong et al. (2014), each of the 150 contexts was completed by a) the semantically expected noun (with the highest cloze 
136 probability for the specific context; EXP), b) an unexpected but somewhat plausible noun (USP),

137 and c) an unexpected, implausible noun (ANOM), resulting in a total of 450 sentence pairs (see

138 Table 1 for sample sentence pairs; the complete set of sentence pairs is provided in Supplemental

139 Table S1). To investigate whether the possible construction of overall sentence meaning was

140 crucial for late positivities, the materials in the ANOM condition were subdivided on the basis of

141 a pretest. Some of the sentences pairs in the ANOM condition contained critical nouns that allowed

142 for a possible real-life meaning (ANOM-Pos; 45 sentence pairs), the other sentence pairs did not

143 (ANOM-Impos; 105 sentence pairs). Fifty additional moderately constraining sentence pairs

144 completed by their expected critical noun were used as fillers to balance the proportion of sentence

145 pairs completed by expected versus unexpected nouns. Sentence material were either German

146 translations of stimuli used in DeLong et al. (2014) or constructed in the same fashion by the

147 experimenters. Where possible, critical nouns of the expected condition were re-used with

148 different sentences in the other two conditions $(53.3 \%$ of critical words were used three times,

$14931.1 \%$ were used twice, and $15.6 \%$ were used only once). Since German nouns are coded for

150 gender (masculine, feminine, neutral), all three completions of a particular sentence pair had the

151 same grammatical gender. Written word frequency, word length and orthographic neighborhood

152 size of the critical nouns were matched between the three main conditions (see Table 2). Note that

153 the Pos and Impos items within the ANOM condition were not balanced with respect to these 154 factors.

\section{$155 \quad 2.2$ Cloze probability norming}

156 Stimulus norming for critical noun cloze probability was conducted in a separate sentence

157 completion task with 36 volunteers (native speakers of German, mainly students). They were

158 compensated with course credit and did not participate in the EEG study. Contexts were truncated 
159 prior to the critical noun, and participants were asked to complete the second sentence with a single

160 noun that came to their mind first and fitted with the preceding context. Every context ended with

161 the three German indefinite articles, in the order masculine, feminine, and neuter, thus allowing

162 nouns of any grammatical gender. Cloze probability was calculated as the proportion of

163 participants who completed a particular sentence pair with a particular noun. The cloze probability

164 of the most frequent noun equals the contextual constraint of a given sentence pair. Sentence pairs

165 with a cloze probability of $50 \%$ or higher were considered highly constraining and included in the

166 study. Filler sentences had a cloze probability of $40 \%$ or higher. Table 2 shows mean cloze

167 probabilities for the experimental and filler conditions.

\section{$168 \quad 2.3$ Plausibility rating}

All 450 sentence pairs, truncated after the critical noun, were rated for plausibility ("How

170 plausible is the sentence pair's meaning...") on a scale of 1 (not plausible) to 5 (highly plausible)

171 by eight independent German raters who did not participate in the EEG study. Table 2 presents

172 mean plausibility ratings of all conditions. Following DeLong et al. (2014), mean plausibility was

173 greater than 1.5 in the EXP and USP conditions, and less than or equal to 1.5 in the ANOM

174 condition. The plausibility ratings differed significantly between all conditions (see Table 3 ).

\section{$175 \quad 2.4$ Possibility rating}

All 450 sentence pairs, truncated after the critical noun, were rated for possibility ("How

177 possible (in real-life) is the sentence pair's meaning...”) by the same eight raters, on a scale of 1

178 (impossible) to 4 (possible). Table 2 specifies mean possibility ratings for all conditions. Similar

179 to the cut-off for Plausibility, mean possibility ratings were greater than 1.5 in the EXP, USP and

180 ANOM-Pos conditions, but equal to or less than 1.5 in the ANOM-Impos condition. The ratings 
181 of all conditions differed significantly from each other (see Table 3). Participants performed both

182 plausibility and possibility ratings at the same time. No examples were provided to avoid biasing

183 the raters' judgements. Correlations between plausibility and possibility ratings are displayed in

184 Supplemental Analysis S1.

185 In the main experiment, each participant was presented with one of three 200-item lists,

186 with contexts and critical nouns used once per list (except for four critical nouns that occurred

187 twice per list, in different contexts). Lists 1, 2, and 3 were presented to 12,10 and 10 participants,

188 respectively. Every list consisted of 50 predictable, expected nouns, 50 unexpected plausible

189 nouns, 50 unexpected implausible (ANOM) nouns, and 50 fillers. Approximately one third of the

190 ANOM nouns was rated possible (list 1: 17, list 2: 16, list 3: 12), the remaining two thirds were

191 rated impossible. Fifty comprehension questions followed $25 \%$ of sentence pairs at random

192 intervals. Three additional sentence pairs preceded every list to familiarize participants with the

193 task. Sentence pairs within a list were randomized across subjects.

\section{$194 \quad 2.5$ ERP Participants}

195 Thirty-two students $(23 \mathrm{f}, 9 \mathrm{~m})$ participated in the experiment after giving written informed

196 consent. They were compensated with course credit or cash (7.50€/hour). Mean age was 25.3

197 years (19-34). All participants were monolingual native speakers of German and right-handed

198 (assessed via Edinburgh Handedness Inventory, Oldfield, 1971). Eight participants reported a left-

199 handed parent or sibling, one reported two left-handed relatives. All participants reported normal

200 or corrected-to-normal vision. One additional participant was tested but excluded from analysis

201 because of a technical problem during the experiment. The study protocol was conducted in

202 accordance with ethical standards of the Declaration of Helsinki and approved by the local ethics

203 committee of the University of Münster (approval number \#2016-42-LQ). 


\subsection{Procedure}

205 The experiment consisted of a single two-hour-session conducted in a quiet and dimly lit

206 room at the Westfälische Wilhelms-Universität Münster. Participants were seated approximately

$2071 \mathrm{~m}$ in front of a LED monitor (BenQ, model XL2420T, $144 \mathrm{~Hz}, 24$ 'W) and read sentence pairs

208 for comprehension. The experiment was set up using Presentation software (NeuroBehavioral

209 Systems, Version 16.3). Stimuli were presented visually, in black type (RGB: 0, 0, 0; Arial 48 pt)

210 on a grey background (RGB: 148, 148, 148). The experiment was divided into eight blocks of

211 approximately six minutes length, with two-minute breaks between blocks. Every trial started with

212 a fixation cross $(500 \mathrm{~ms})$ in the center of the screen, followed by the first sentence of a pair

213 presented in its entirety. Participants advanced to the critical sentence via button press. This

214 sentence including the critical word was presented with a rapid serial visual presentation technique

215 (RSVP), each word presented centrally for $200 \mathrm{~ms}$, with a stimulus onset asynchrony of $500 \mathrm{~ms}$.

216 Yes/no comprehension questions followed $25 \%$ of sentence pairs at random intervals. Participants

217 responded with two buttons on a response pad (Cedrus, model RB-830) with response buttons

218 counterbalanced across participants and lists. Comprehension questions appeared after the critical

219 noun sentence. In case of a question, participants' button press advanced to the next trial, otherwise

220 the next sentence pair appeared automatically after two seconds.

221 Material, design and procedure were almost identical to DeLong et al.'s second experiment

222 except for the following differences. First, DeLong et al.'s sentence material was translated into

223 German or constructed using the same sentence structure. Second, mean constraint of discourse

224 contexts and mean cloze probability of expected critical words were lower than in DeLong et al.

225 (.77 vs .89, respectively). Third, sentence pairs were not rated for possibility in DeLong's study. 
226 Fourth, 32 participants completed the present EEG experiment, 24 students participated in DeLong

227 et al.'s second study.

$228 \quad 2.7$ Electroencephalographic recording parameters

229

EEG was recorded from $32 \mathrm{Ag} / \mathrm{AgCl}$-electrodes attached to a WaveGuard 32-channel cap

230 (ANT, Advanced Neuro Technology). Electrodes were placed according to the International 10-

23120 convention (Jasper, 1958), and an average reference was used (see Fig. 1 for scalp sites). Blinks

232 and vertical eye movements were monitored from electrodes placed above and below the left eye,

233 and horizontal eye movements were monitored from two electrodes placed on the outer canthi.

234 Impedances were kept below $5 \mathrm{k} \Omega$. The EEG was continuously recorded with ASA (Advanced

235 Source Analysis, version 4.7.3.1, ANT). Data collection and evaluation were controlled by ExMan

236 (Experiment Manager; MS Excel worksheet with active macros). EEG was amplified (ExG 20x,

237 fixed $=50 \mathrm{mV} / \mathrm{V}$ ), low pass filtered (finite impulse response filter, cut-off frequency $=.27 \mathrm{x}$

238 sampling rate) and continuously digitized at a sampling rate of 256 samples/second.

\section{$239 \quad 2.8$ Data analysis}

240 Before averaging, the EEG signal was filtered using a Butterworth half-amplitude bandpass

241 FIR-filter $(0.1 \mathrm{~Hz}, 20 \mathrm{~Hz}, 12 \mathrm{db} / \mathrm{oct})$. Vertical eye movements were corrected with principal 242 component analysis (Ille, Berg, \& Scherg, 2002). Additionally, seven electrodes (0.7\%) were

243 interpolated (see Supplemental Table S2). The EEG was re-referenced offline to the algebraic

244 mean of left and right mastoids and averaged for each experimental condition, time-locked to the 245 critical noun onset. Before averaging, trials contaminated by artefacts (specified as voltage 246 changes exceeding $\pm 75 \mu \mathrm{V}$ during the epoch) were rejected offline (on average $4.23 \%$ of all trials, 
$247 \mathrm{SD}=4.80$ ). ERPs were calculated for epochs extending from $500 \mathrm{~ms}$ pre- to $1500 \mathrm{~ms}$ post-stimulus

248 onset, thus using a pre-stimulus baseline of $500 \mathrm{~ms}$.

In a first step, mass univariate analyses were conducted to compare spatial and temporal properties of possible ERP effects found in the present experiment to the findings by DeLong et al. (2014). ERPs from the three pairwise comparisons, [USP minus EXP], [ANOM minus EXP], and [ANOM minus USP], were submitted to repeated measures, two-tailed t-tests at all sampled time points between $250 \mathrm{~ms}$ and $1050 \mathrm{~ms}$ (206 total time points) at all 30 scalp electrodes, resulting in 6180 total comparisons for each condition contrast. To control the number of false discoveries, the Benjamini and Yekutieli (2001) procedure was applied using a false discovery rate level of $2565 \%$.

In a second step, mean amplitudes were analyzed by first conducting ANOVAs with three levels of noun type (EXP, USP and ANOM) to compare the present results directly to those reported in DeLong et al. (2014). These analyses were complemented by pairwise t-tests between the four levels of noun type (EXP, USP, ANOM-Pos, and ANOM-Impos). ANOVAs were applied to the data from three time windows: a) over all 30 electrode sites between $300 \mathrm{~ms}$ and $500 \mathrm{~ms}$ (N400), b) over seven (left) anterior electrode sites [Fp1, Fpz, F7, F3, Fz, FC5, T7] between 600 ms and 1000 ms (frontal positivity), c) over seven posterior electrode sites [Cz, CP1, CP2, P3, Pz, P4, POz] between $600 \mathrm{~ms}$ and $1000 \mathrm{~ms}$ (posterior positivity; see Fig. 1 for electrode placement). Scalp regions and temporal windows were based on DeLong et al.'s (2014) second experiment. To confirm the left lateralization of the anterior positivity, we extended the corresponding ANOVA by the factor hemisphere (left, right), and included equivalent right hemisphere electrodes (Fp2, F4, F8, Fc6, and T8) while excluding midline electrodes Fz and Fpz. If sphericity was violated, ANOVA p-values and degrees of freedom were corrected using epsilon correction 
270 (Greenhouse Geisser) for repeated measures with more than one degree of freedom. Significance

271 levels of pairwise $\mathrm{t}$-tests were Bonferroni-adjusted (t-tests following ANOVAs with three levels

272 of noun type: $\mathrm{p}_{\text {boncor }}<.0167$, $\mathrm{t}$-tests comparing all four levels of noun type: $\mathrm{p}_{\text {boncor }}<.0083$ ).

273

274

\section{Results}

275

276

277 278

279

280

281

282

283

284 285 286

287

288

289

\subsection{Behavioral results}

Participants correctly answered an average of 96.7\% (median 97\%, range $=90-100 \%$ ) of yes/no comprehension questions, suggesting they comprehended the sentence pairs during the experiment.

\subsection{ERP results}

\subsubsection{Mass univariate analyses.}

The first mass univariate analysis focused on predictability, comparing USP versus EXP nouns (see Fig. 2, top). There was a widespread N400 effect, with ERPs to USP nouns being more negative than ERPs to EXP nouns. This negativity lasted from approximately 250 to $500 \mathrm{~ms}$. Starting shortly before the offset of the N400, between approximately 550 and $1000 \mathrm{~ms}$, USP nouns were more positive than EXP nouns, particular over left frontal and left lateral temporoparietal scalp sites.

The second mass univariate analysis looked at plausibility, comparing ANOM versus EXP nouns (see Fig. 2, middle). Again, a widespread N400 effect emerged, with ERPs to ANOM nouns being more negative than ERPs to EXP nouns, between approximately $250 \mathrm{~ms}$ and $500 \mathrm{~ms}$. By 
290 about $600 \mathrm{~ms}$, a positivity of ANOM relative to EXP nouns emerged and continued up to the end

291 of the time window $(1050 \mathrm{~ms})$, being most prominent over central and posterior scalp sites.

292 The third mass univariate analysis compared ANOM versus USP nouns (see Fig. 2,

293 bottom). Between $300 \mathrm{~ms}$ and $450 \mathrm{~ms}$, ERPs to ANOM nouns were more negative than ERPs to

294 USP nouns. In addition, from approximately $600 \mathrm{~ms}$ to the end of the time window (1050 ms),

295 ERPs to ANOM nouns were more positive than ERPs to USP nouns at posterior scalp locations.

296 In contrast, ERPs to USP nouns were more positive than ERPs to ANOM nouns over lateral frontal

297 scalp sites between approximately 700 to $900 \mathrm{~ms}$. In all three mass-univariate analyses, significant 298 p-values are $p_{\text {adj }}<.05$.

\subsubsection{Analyses of variance.}

For visual inspection, Fig. 3 shows the grand average ERPs of all 32 participants over 30 scalp channels. Topographic scalp maps of ERP mean amplitude voltage differences can be seen in Fig. 4, and four representative anterior and posterior channels are shown in Fig. 1. In line with the results from mass univariate analyses described above, all figures reveal N400 effects for both USP and ANOM nouns relative to EXP nouns, a post-N400 positivity for ANOM nouns over posterior channels, and a post-N400 positivity for USP nouns over anterior channels. Early components (P1, N1, and P2) do not differ as a function of noun type. Tables 4 and 5 provide mean amplitudes of the four noun types and detailed results of pairwise t-tests between conditions.

\subsubsection{300-500 ms.}

An ANOVA with three levels of noun type over all 30 electrode sites revealed a main effect

$\left[F(1.60,49.46)=74.98, p<.001, \varepsilon_{\mathrm{GG}}=0.80, \eta_{\mathrm{p}}^{2}=0.39\right]$. ANOM nouns showed the largest

311 negativity $(-2.89 \mu \mathrm{V})$, followed by USP nouns $(-1.54 \mu \mathrm{V})$ and EXP nouns $(0.83 \mu \mathrm{V})$. Post-hoc t- 
312 tests are displayed in Fig. 5. The pairwise t-tests between all four noun types revealed significant

313 differences between all conditions $(t(31) \geq 4.38, p<.001)$ except for the comparison of ANOM-

314 Pos $(-3.01 \mu \mathrm{V})$ and ANOM-Impos nouns $(-2.82 \mu \mathrm{V} ; t(31)=-0.72, p=.479)$.

\subsubsection{600-1000 ms posterior scalp sites.}

An ANOVA with three levels of noun type, conducted over seven posterior electrode sites,

317 showed a main effect $\left[F(2,62)=21.06, p<.001, \eta_{\mathrm{p}}{ }^{2}=0.19\right]$. ANOM nouns had the largest

318 positivity $(3.09 \mu \mathrm{V})$, followed by USP nouns $(1.38 \mu \mathrm{V})$ and EXP nouns $(0.98 \mu \mathrm{V})$. Post-hoc t-tests

319 are displayed in Fig. 5. Pairwise t-tests revealed significant differences between EXP and ANOM-

320 Pos nouns $(t(31)=-4.29, p<.001)$, EXP and ANOM-Impos nouns $(t(31)=-5.40, p<.001)$, USP

321 and ANOM-Pos nouns $(t(31)=-4.75, p<.001)$, and USP and ANOM-Impos nouns $(t(31)=-4.87$,

$322 p<.001)$. No reliable difference was found between EXP and USP nouns $(t(31)=-1.31, p=.200)$

323 and between the two types of ANOM nouns (ANOM-Pos $=2.95 \mu \mathrm{V}$, ANOM-Impos $=3.16 \mu \mathrm{V}$;

$324 t(31)=-0.72, p=.477)$.

\subsubsection{600-1000 ms anterior scalp sites.}

The extended ANOVA indicated a left lateralization of the effect (see Supplemental 327 Analysis S2). Therefore, we restricted our analysis to those electrodes analyzed in DeLong et al. (2014). Over the seven left anterior electrodes, the ANOVA with three levels of noun type revealed

a main effect $\left[F(2,62)=6.13, p=.004, \eta_{\mathrm{p}}^{2}=0.08\right]$. USP nouns showed the greatest positivity

$p<.001)$ and from ANOM-Pos nouns $(t(31)=-2.88, p=.007)$. The differences between USP and 
334 nouns $(\operatorname{diff}=0.54 \mu \mathrm{V} ; \mathrm{t}(31)=-1.52, p=.138)$ were not significant. Although ANOM-Pos (1.96

$335 \mu \mathrm{V})$ and ANOM-Impos nouns $(1.33 \mu \mathrm{V})$ differed by $0.64 \mu \mathrm{V}$, this difference also did not reach

336 significance $(t(31)=1.89, p=.068)$.

Whereas there were no differences in other temporal and/or spatial analysis windows,

338 ANOM-Pos and ANOM-Impos thus seem to have a different impact on late anterior positivity.

339 Given that different items were compared in the ANOM-Pos and ANOM-Impos conditions, we

340 ran a regression analysis to assess possible effects of critical word characteristics that may cause

341 amplitude differences between nouns. An amplitude calculation for each item averaged over

342 participants is inadequate for exploring factors in multiple regression designs, because it disregards

343 interparticipants' variability. Therefore, we used the method suggested by Lorch and Myers

344 (1990). For every participant, we extracted amplitudes of individual words and fitted a linear

345 regression with factors plausibility, possibility, word length, word frequency, and orthographic

346 neighborhood size (without interaction terms). For every predictor, the resulting $32 \mathrm{t}$-values

347 entered a one-sample t-test. Only the effect of word length on amplitude was significantly different

348 from zero $(t(31)=3.25, p=.003)$. See Supplemental Table S3 for detailed results. Note that the

349 effect of Possibility failed significance, and even the Plausibility effect, which entails a within-

350 item comparison, is much weaker in this analysis.

\section{General discussion}

In this study with German materials and participants, we investigated the electrophysiological signatures of different types of contextual fit - from predictable and thus expected, to highly implausible continuations of short discourses consisting of sentences pairs.

355 Whereas no reliable differences were present before $300 \mathrm{~ms}$, graded N400 effects for target nouns 356 were observed as a function of their predictability and plausibility in the discourse. Relative to 
357 highly predictable nouns, amplitudes were more negative for unexpected but plausible

358 continuations, and again more negative for implausible continuations. Whether or not the

359 implausible noun was a somewhat strange but in principle possible continuation of the preceding

360 discourse had no impact on the N400. In the time window following the N400, positivities with

361 different scalp signatures were observed that differed as a function of noun type. At posterior

362 electrode sites, the $600-1000 \mathrm{~ms}$ time window revealed similar amplitudes for highly predictable

363 and unpredictable but plausible continuations. Relative to these two continuations, there was

364 enhanced positivity for both implausible noun types - which showed very similar amplitudes. At

365 anterior sites, predictable and completely impossible continuations had similar amplitudes, but

366 predictable nouns had a less positive amplitude than both unpredictable plausible and implausible,

367 but still possible continuations, which did not differ.

In the following, we compare our outcomes to the original study (experiment 2) by DeLong

369 and colleagues (2014) that we aimed to replicate, and evaluate our results against the predictions

370 made for continuations that are quite implausible, but for which a real-world interpretation can be

371 constructed given the discourse. We discuss the distinction between anterior and posterior late

372 positivities and the potential processing functions that may underlie them.

373 4.1 Replication of DeLong, Quante, and Kutas (2014)

The data patterns relevant for the replication of DeLong et al. (2014), with three conditions

375 (EXP, USP and ANOM) in three time windows (N400, Anterior Positivity, Posterior Positivity),

376 show a striking similarity between the two studies, illustrated in Fig. 5.

The data for the N400 from the two studies show a very similar pattern - ignoring the

378 position of the zero line. Relative to expected continuations, negativity is enhanced for unexpected 
379 but plausible (USP) nouns, and again more so for implausible (ANOM) nouns. The results for the

380 N400 thus fully replicate the graded negativity reported by DeLong et al. Note that the possibility

381 to create an interpretation for some implausible continuations had no effect on N400 amplitude,

382 since our two anomalous conditions did not differ.

The posterior positivity after the N400 also shows the same pattern as obtained by

384 DeLong and colleagues (2014), with significant differences between the expected (EXP) and anomalous continuations (ANOM), between unexpected (USP) and anomalous words, but not

386 between EXP and USP, the expected and unexpected continuations. Again, exactly the same

387 pattern with the same significances was observed in both studies. Moreover, the analysis with four

388 noun types showed no difference between the possible and impossible anomalous continuations.

389 Finally, the anterior positivity again showed a similar pattern in both studies, but with somewhat

390 different significances. Whereas in both studies, amplitudes for expected (EXP) and unexpected

391 plausible (USP) nouns differ, and amplitudes for expected and anomalous nouns do not differ, the

392 difference between the unexpected plausible and anomalous nouns that was reliable in DeLong et

393 al. failed significance in our data. The analysis with four noun levels gives an indication why this

394 might be the case. In this analysis, the anomalous nouns that have a possible interpretation given

395 the preceding discourse do show a significant difference to the expected nouns, thus coinciding

396 with the unpredictable but plausible nouns. The difference to the impossible anomalous nouns

397 remains insignificant. Note however that the post-hoc regression analysis, which takes into account

398 between-item differences in the analyses of possibility effects, questions whether these differences

399 can be attributed to possibility.

400 Thus, with one interesting exception we closely replicate Experiment 2 by DeLong and 401 colleagues (2014), with German materials - mainly but not exclusively translated from DeLong et 
402 al. (2014), with somewhat lower predictability of the predictable, expected nouns, and with

403 German native speakers. We believe this replication of a dissociation between anterior and 404 posterior positivity in largely overlapping, post-N400 time windows to be an important 405 contribution to the growing evidence for a functional difference associated with these two late 406 positivities. As DeLong and colleagues, and unlike other studies, we show this relatively new 407 dissociation with the same population within one experiment. In the following, we discuss our 408 findings relative to data, hypotheses and models proposed by others.

\subsection{N400 and late positivities}

The N400 effects show that relative to an anomalous noun, an unexpected noun that is

411 nevertheless a perfectly plausible continuation shows a smaller negativity. This graded negativity,

412 relative to the predicted continuation, replicates findings from many studies that show amplitude

413 negativity to depend on the degree of deviation from the condition that serves as reference (see

414 Kutas \& Federmeier, 2011, for an overview).

415 The late positivity observed in our data seems to come in two guises. There is a bilateral, 416 posterior positivity that separates expected and unexpected but plausible continuations from 417 implausible, anomalous continuations - with no difference between those for which a possible, 418 real-world meaning (ANOM-Pos) can be constructed and those for which this is not the case 419 (ANOM-Impos). A second late positivity, with anterior, left-lateralized scalp distribution, seems 420 to distinguish between nouns for which an interpretation in the given discourse is possible but 421 unexpected (USP and ANOM-Pos nouns) on the one hand, and predictable words on the other.

\section{$422 \quad 4.3$ Posterior late positivity}


The posterior late positivity observed in our data resembles the P600 that has been

424

425

426

427

428

430

431

432

433

434

435

436

437

438

439

440

441

442

443

444

445

commonly associated with syntactic violations (e.g., Hagoort, Brown, \& Groothusen, 1993) or syntactic complexity (e.g., Friederici, Hahne, \& Saddy, 2002; Kaan \& Swaab, 2003). This changed some fifteen years ago, when late positivities were reported for words that constituted thematicrole violations (e.g., At breakfast the eggs would eat) which are semantic in nature (Kolk, Chwilla, van Herten, \& Oor, 2003; Kuperberg, Sitnikova, Caplan, \& Holcomb, 2003; Hoeks, Stowe, \& Doedens, 2004; see Brouwer, Fitz, \& Hoeks, 2012, for an overview). Such "semantic illusions" had no impact on the N400 but showed in late positivities, with a central-posterior/parietal scalp topography that resembles the "syntactic" P600. This "semantic" P600 again fired the debate on its functional significance. Most proposed models and views adhere to two processing streams semantic and syntactic - whose outputs can conflict with each other, which is reflected in the P600 (cf. Kim \& Osterhout, 2005; Kolk \& Chwilla, 2007; Kuperberg, 2007; Bornkessel-Schlesewsky \& Schlesewsky, 2008; Hagoort, Baggio, \& Willems, 2009; Kos, Vosse, van den Brinke, \& Hagoort, 2010; Metzner, Malsburg, Vasishth, \& Rösler, 2017; see Brouwer et al., 2017, for an overview and a different model).

In their seminal review of data from about 60 studies, Van Petten and Luka (2012) conclude that posterior late positivity is associated with attempts at reanalysis when a problem is detected be it a syntactic or semantic incongruency or anomaly. Our late posterior positivities for all anomalous continuations fit this picture. Kuperberg (2013) prominently put late positivities into the perspective of prediction, suggesting that the posterior late positivities reflect processing costs when the incoming word disconfirms predicted events or event structure. This is the case even for semantic illusions (e.g., The cat that from the mice fled, incoming word underlined, Kolk et al., 2003) in which the incoming words semantically fit the event, but their thematic roles violate event 
446 structure. In our data, all anomalous continuations show a posterior negativity. Clearly, impossible

447 continuations violate event structure (often but not always because of selection restriction

448 violations): "excuse" is not a viable candidate for a snowman's nose. This is different for the

449 unexpected but plausible continuations: lacking a carrot, a banana can serve as a snowman's nose,

450 and is thus compatible with the event of snowman construction. Consequently, our expected and

451 unexpected but plausible words do not differ in late posterior positivity. Note that relative to these

452 two conditions, and in contrast to our prediction, a clear late posterior positivity was evident for

453 both types of anomalous continuations, those that are completely impossible and those for which

454 an admittedly strange meaning could be constructed (e.g., To save space, she bought herself a pig

455 (expected: a loft bed) in the store.). Following the logic by Van Petten and Luka, both anomalies

456 initiate the reprocessing of prior input, and in Kuperberg's view, both anomalies seem severe 457 enough to violate event structure.

458 4.4 Anterior late positivity

Finally, we consider the anterior post-N400 positivity observed in our data. In the overall 460 analysis, unexpected but plausible continuations (the banana as nose for the snowman) and implausible but still in some way possible continuations (the woman who bought herself a pig to 462 save space) group together. First, they both differ from expected, highly predictable continuations 463 (the carrot for a snowman's nose, a loft bed to save space) and second, both continuations allow 464 for a revision of the discourse on the basis of the meaning of the unexpected words. Note that the 465 differences observed here may be due to item characteristics, as the regression analysis indicated. 466 Although these data, given that they involve different items, should be treated with caution, it is 467 interesting that similar late positivities with a (left) frontal scalp distribution have been observed 468 when words are not predicted but semantically possible, given the preceding context (Federmeier, 
469 Wlotko, De Ochoa-Dewald, \& Kutas, 2007; DeLong, Urbach, Groppe, \& Kutas, 2011; Thornhill

470 \& Van Petten, 2012; Van Petten \& Luka, 2012; DeLong, Quante, \& Kutas, 2014). As noted by

471 Van Petten and Luka, and as is the case in our data, frontal late positivities follow an N400 - which

472 is not always the case for posterior positivities. This co-occurrence is taken as an index for the 473 sensitivity of frontal positivities to semantic predictability.

474 The exact functional significance of anterior late positivity is still under debate. Most researchers agree that it signals disconfirmed lexical prediction or lexical "prediction error" (Van

476 Petten \& Luka, 2012; Kuperberg, 2013, for overviews), and that the presence of a moderately or 477 highly constraining context that can trigger updating is a prerequisite (Boudewyn et al., 2015).

478 Note that both requirements apply to the two conditions in which we observed late frontal 479 positivity. Taking these constraints as given, it remains unclear what processing costs occur after 480 disconfirmed prediction. Do they involve inhibition of the predicted word - a hypothesis 481 formulated with quite some foresight by Marta Kutas (1993), or are processing costs due to 482 revising and updating working memory to integrate the unexpected continuation (Federmeier et 483 al. 2007; Kuperberg, 2013)? In an ingenious study, Brothers, Swaab, and Traxler (2016) observed 484 late frontal positivity for words that were not predicted by their participants - who were told to 485 actively predict continuations of sentences and who indicated afterwards whether the continuation 486 presented was the one they predicted or not. With full, trial by trial control of prediction, Brothers 487 et al., could distinguish between specific lexical prediction and general contextual support - which 488 our design does not allow. Given that they also observed early (pre-N400) effects of prediction, 489 the authors conclude that the left-lateralized anterior positivity reflects prediction-related, post 490 lexical update and revision mechanisms. Given the importance of such mechanisms for prediction 
491 in language, such anterior late positivities should be investigated further, with better control over

492 item characteristics as is the case in our study.

\section{$493 \quad 4.5$ Limitations}

It is important to point out that our materials were not explicitly constructed for the distinction between ANOM-Impos and ANOM-Pos and that materials were not balanced (45 vs. 105 sentence pairs). As the regression analysis showed, items differed in length, which had an impact on the late anterior positivities. As DeLong et al.'s (2014) sentence pairs were not rated for possibility, it is not clear whether the minor discrepancies between the results of the two studies arose from potential differences of the nouns in the ANOM conditions. We also should note that overall contextual constraint was slightly lower in our study than in DeLong et al. which we aimed to replicate. Still, despite their post-hoc flavor, our results on (im)possibility provide an interesting perspective on the possibility of contextual integration of even quite implausible continuations - a good reason to consider this dimension in the future.

\subsection{Conclusions}

With German materials and participants, we replicated results of DeLong and colleagues (2014) and showed an impact of three types of constraint in sentence processing: predictability,

507 plausibility and possibility. We observed graded effects on the N400, with the smallest negativity

508 for expected continuations, followed by plausible but not expected alternatives, and with the

509 largest negativity for implausible, anomalous continuations. Next, despite both being unexpected,

510 plausible and implausible words show different patterns of posterior late positivity, arguing for a 511 dissociation of predictability and plausibility. Finally, we believe that the distinction between 
512 possible and impossible continuations, both being implausible, should be taken into account in 513 studies on prediction and processing words in context. 
515 We are deeply grateful to Katherine DeLong and Marta Kutas for their invaluable support,

516 and thank Dan Ke, Christian Bürger, René Michel and Daniel Kluger for their assistance in data

517 collection and analysis.

518 


\section{References}

520

Benjamini, Y., \& Yekutieli, D. (2001). The control of the false discovery rate in multiple

521 testing under dependency. Annals of Statistics, 1165-1188.

522

Bornkessel-Schlesewsky, I., \& Schlesewsky, M. (2008). An alternative perspective on

523 “semantic P600" effects in language comprehension. Brain Research Reviews, 59(1), 55-73.

524 doi:10.1016/j.brainresrev.2008.05.003

525 Boudewyn, M. A., Long, D. L., \& Swaab, T. Y. (2015). Graded expectations: Predictive

526 processing and the adjustment of expectations during spoken language comprehension. Cognitive,

527 Affective, \& Behavioral Neuroscience, 15(3), 607-624. doi:10.3758/s13415-015-0340-0

528

Brothers, T., Swaab, T. Y., \& Traxler, M. J. (2015). Effects of prediction and contextual

529

support on lexical processing: Prediction takes precedence. Cognition, 136, 135-149.

530 doi:10.1016/j.cognition.2014.10.017

531

Brouwer, H., Crocker, M. W., Venhuizen, N. J., \& Hoeks, J. C. (2017). A

532 Neurocomputational Model of the N400 and the P600 in Language Processing. Cognitive Science, 533 41(S6), 1318-1352. doi:10.1111/cogs.12461

Brouwer, H., Fitz, H., \& Hoeks, J. (2012). Getting real about semantic illusions: rethinking 535 the functional role of the P600 in language comprehension. Brain Research, 1446, 127-143. 536 doi:10.1016/j.brainres.2012.01.055

Coltheart, M., Davelaar, E. J., Jonasson, J. T., \& Besner, D. (1977). Access to the Internal

538 Lexicon. In S. Dornic (Ed.), Attention and Performance VI. Proceedings of the Sixth International 
539 Symposium on Attention and Performance, Stockholm, Sweden, July 28-August 1, 1975 (pp. 535-

540 555). Hillsdale, NJ: Lawrence Erlbaum Associates.

541 DeLong, K. A., Quante, L., \& Kutas, M. (2014). Predictability, plausibility, and two late

542 ERP positivities during written sentence comprehension. Neuropsychologia, 61, 150-162.

543 doi:10.1016/j.neuropsychologia.2014.06.016

544 DeLong, K. A., Urbach, T. P., Groppe, D. M., \& Kutas, M. (2011). Overlapping dual ERP

545 responses to low cloze probability sentence continuations. Psychophysiology, 48(9), 1203-1207.

546 doi:10.1111/j.1469-8986.2011.01199.x

DeLong, K. A., Urbach, T. P., \& Kutas, M. (2005). Probabilistic word pre-activation during language comprehension inferred from electrical brain activity. Nature Neuroscience, 8(8), 1117 1121. doi:10.1038/nn1504

Dennis, A. R., \& Valacich, J. S. (2014). A replication manifesto. AIS Transactions on

Replication Research, 1(1), 1. doi:10.17705/1atrr.00001

552

Dikker, S., \& Pylkkänen, L. (2011). Before the N400: Effects of lexical-semantic violations 553 in visual cortex. Brain and Language, 118(1), 23-28. doi:10.1016/.band1.2011.02.006

Federmeier, K. D., Wlotko, E. W., De Ochoa-Dewald, E., \& Kutas, M. (2007). Multiple 555 effects of sentential constraint on word processing. Brain Research, 1146, 75-84. 556 doi:10.1016/j.brainres.2006.06.101

Forster, K. I. (1981). Priming and the effects of sentence and lexical contexts on naming

558 time: Evidence for autonomous lexical processing. The Quarterly Journal of Experimental

559 Psychology, 33(4), 465-496. doi:10.1080/14640748108400804 
561 reflecting aspects of syntactic complexity and syntactic repair. Journal of Psycholinguistic

562 Research, 31(1), 45-63.

563 Geyer, A., Holcomb, P. J., Kuperberg, G. R., \& Perlmutter, N. (2006). Plausibility and 564 sentence comprehension. An ERP study. Cogn. Neurosci. Suppl., Abstract, 1-1.

565 Hagoort, P., Baggio, G., \& Willems, R. M. (2009). Semantic unification. In The Cognitive 566 Neurosciences, 4th ed. (pp. 819-836). MIT press.

567 Hagoort, P., Brown, C., \& Groothusen, J. (1993). The syntactic positive shift (SPS) as an 568 ERP measure of syntactic processing. Language and Cognitive Processes, 8(4), 439-483. 569 doi:10.1080/01690969308407585

570

Hoeks, J. C., Stowe, L. A., \& Doedens, G. (2004). Seeing words in context: the interaction 571 of lexical and sentence level information during reading. Cognitive Brain Research, 19(1), 59-73. 572 doi:10.1016/j.cogbrainres.2003.10.022 speed predict anticipatory spoken language processing in the visual world. Language, Cognition and Neuroscience, 31(1), 80-93. doi:10.1080/23273798.2015.1047459

577 filters based on artifact and brain signal topographies. Journal of Clinical Neurophysiology, 19(2), 578 113-124. doi:10.1097/00004691-200203000-00002 
580 form and meaning: Evidence from brain potentials. Journal of Memory and Language, 86, 157-

581 171. doi:10.1016/j.jml.2015.10.007

582

Jasper, H. H. (1958). Report of the committee on methods of clinical examination in

583 electroencephalography: 1957. Electroencephalography and Clinical Neurophysiology, 10(2),

584 370-375. doi:10.1016/0013-4694(58)90053-1

585

Kaan, E., \& Swaab, T. Y. (2003). Repair, revision, and complexity in syntactic analysis:

586

An electrophysiological differentiation. Journal of Cognitive Neuroscience, 15(1), 98-110. doi:10.1162/089892903321107855

Kim, A., \& Osterhout, L. (2005). The independence of combinatory semantic processing:

589 Evidence from event-related potentials. Journal of Memory and Language, 52(2), 205-225. doi:10.1016/j.jml.2004.10.002

Kolk, H. H. J., \& Chwilla, D. J. (2007). Late positivities in unusual situations. Brain and 592 Language, 100(3), 257-261. doi:10.1016/j.band1.2006.07.006 capacity in verbal working memory: A study with event-related potentials. Brain and Language, 85(1), 1-36. doi:10.1016/s0093-934x(02)00548-5

597 conflicts between syntax and semantics as revealed by ERPs. Frontiers in Psychology, 1. 598 doi:10.3389/fpsyg.2010.00222 

syntax. Brain Research, 1146, 23-49. doi:10.1016/j.brainres.2006.12.063 us about the dynamics of reading comprehension. In: Unraveling the behavioral, neurobiological, 603 and genetic components of reading comprehension. Miller, B., Cutting, L., \& McCardle, P. (Eds): Baltimore: Paul Brookes Publishing.

Kuperberg, G. R., \& Jaeger, T. F. (2016). What do we mean by prediction in language 606 comprehension? Language, Cognition and Neuroscience, 31(1), 32-59. 607 doi:10.1080/23273798.2015.1102299

608 Kuperberg, G. R., Sitnikova, T., Caplan, D., \& Holcomb, P. J. (2003). Electrophysiological distinctions in processing conceptual relationships within simple sentences. Cognitive Brain Research, 17(1), 117-129. doi:10.1016/s0926-6410(03)00086-7

611 Kutas, M. (1993). In the company of other words: Electrophysiological evidence for single-

612 word and sentence context effects. Language and Cognitive Processes, 8(4), 533-572. 613 doi:10.1080/01690969308407587

614 Kutas, M., \& Federmeier, K. D. (2000). Electrophysiology reveals semantic memory use 615 in language comprehension. Trends in Cognitive Sciences, 4(12), 463-470. doi:10.1016/S1364$616 \quad 6613(00) 01560-6$ Kutas, M., \& Federmeier, K. D. (2011). Thirty years and counting: Finding meaning in the 618 N400 component of the event related brain potential (ERP). Annual Review of Psychology, 62, 619 621-647. doi:10.1016/s1364-6613(00)01560-6 

semantic incongruity. Science, 207(4427), 203-205. doi:10.1126/science.7350657 484-502. doi:10.1162/jocn_a_00328 cognitive research. Journal of Experimental Psychology: Learning, Memory, and Cognition, 16(1), 149-157. doi:10.1037/0278-7393.16.1.149 632 doi:10.1037//0033-295x.88.5.375 naturally: Evidence from combined recordings of eye movements and electric brain potentials. 635 Cognitive Science, 41(S6), 1232-1263. doi:10.1111/cogs.12384 
640 replicate evidence for probabilistic pre-activation of phonology. bioRxiv, 111807. 641 doi:10.1101/111807 643 inventory. Neuropsychologia, 9(1), 97-113. doi:10.1016/0028-3932(71)90067-4 646 processing nouns within passive structures. Cogn. Neurosci. Suppl., Abstract. sentence processing: Distinct effects of semantic relatedness on violations of real-world event/state knowledge and animacy selection restrictions. Journal of Memory and Language, 67(4), 426-448. 650 doi:10.1016/j.jml.2012.07.003 652 on eye movements in reading. Journal of Experimental Psychology: Learning, Memory, and 653 Cognition, 30(6), 1290. scope of facilitation for upcoming words. Journal of Memory and Language, 24(2), 232-252. 656 doi:10.1016/0749-596x(85)90026-9 
661 of context effects. Journal of Verbal Learning and Verbal Behavior, 18(6), 645-659. 662 doi:10.1016/s0022-5371(79)90355-4

663 Szewczyk, J. M., \& Schriefers, H. (2013). Prediction in language comprehension beyond 664 specific words: An ERP study on sentence comprehension in Polish. Journal of Memory and 665 Language, 68(4), 297-314. doi:10.1016/j.jml.2012.12.002

666 Thornhill, D. E., \& Van Petten, C. (2012). Lexical versus conceptual anticipation during 667 sentence processing: Frontal positivity and N400 ERP components. International Journal of 668 Psychophysiology, 83(3), 382-392. doi:10.1016/j.ijpsycho.2011.12.007 van Berkum, J. J. A., Brown, C. M., Zwitserlood, P., Kooijman, V., \& Hagoort, P. (2005).

670 Anticipating upcoming words in discourse: evidence from ERPs and reading times. Journal of 671 Experimental Psychology: Learning, Memory, and Cognition, 31(3), 443. doi:10.1037/0278$672 \quad 7393.31 .3 .443$

673 van Berkum, J. J. A., Zwitserlood, P., Hagoort, P., \& Brown, C. M. (2003). When and how 674 do listeners relate a sentence to the wider discourse? Evidence from the N400 effect. Cognitive 675 Brain Research, 17(3), 701-718. doi:10.1016/s0926-6410(03)00196-4

676 Van Petten, C., \& Luka, B. J. (2012). Prediction during language comprehension: Benefits, 677 costs, and ERP components. International Journal of Psychophysiology, 83(2), 176-190. 678 doi:10.1016/j.ijpsycho.2011.09.015

679 Warren, T., \& McConnell, K. (2007). Investigating effects of selectional restriction 680 violations and plausibility violation severity on eye-movements in reading. Psychonomic Bulletin 681 \& Review, 14(4), 770-775. doi:10.3758/bf03196835 
682 Zwitserlood, P. (1989). The locus of the effects of sentential-semantic context in spoken-

683 word processing. Cognition, 32(1), 25-64. doi:10.1016/0010-0277(89)90013-9

684

685 


\section{Notes}

i We use "predictable" and "expected" interchangeably to characterize continuations that are highly expected given the preceding discourse, with predictability assessed by means of a cloze procedure. 
Figure 1

Representative anterior and posterior scalp channels.

ERPs for EXP, USP, ANOM-Pos and ANOM-Impos nouns. Displayed channels are marked as stars on the electrode montage mapping (E). Dashed-line boxes indicate analyzed time windows (N400: 300-500 ms; post-N400 positivity: 600-1000 ms).
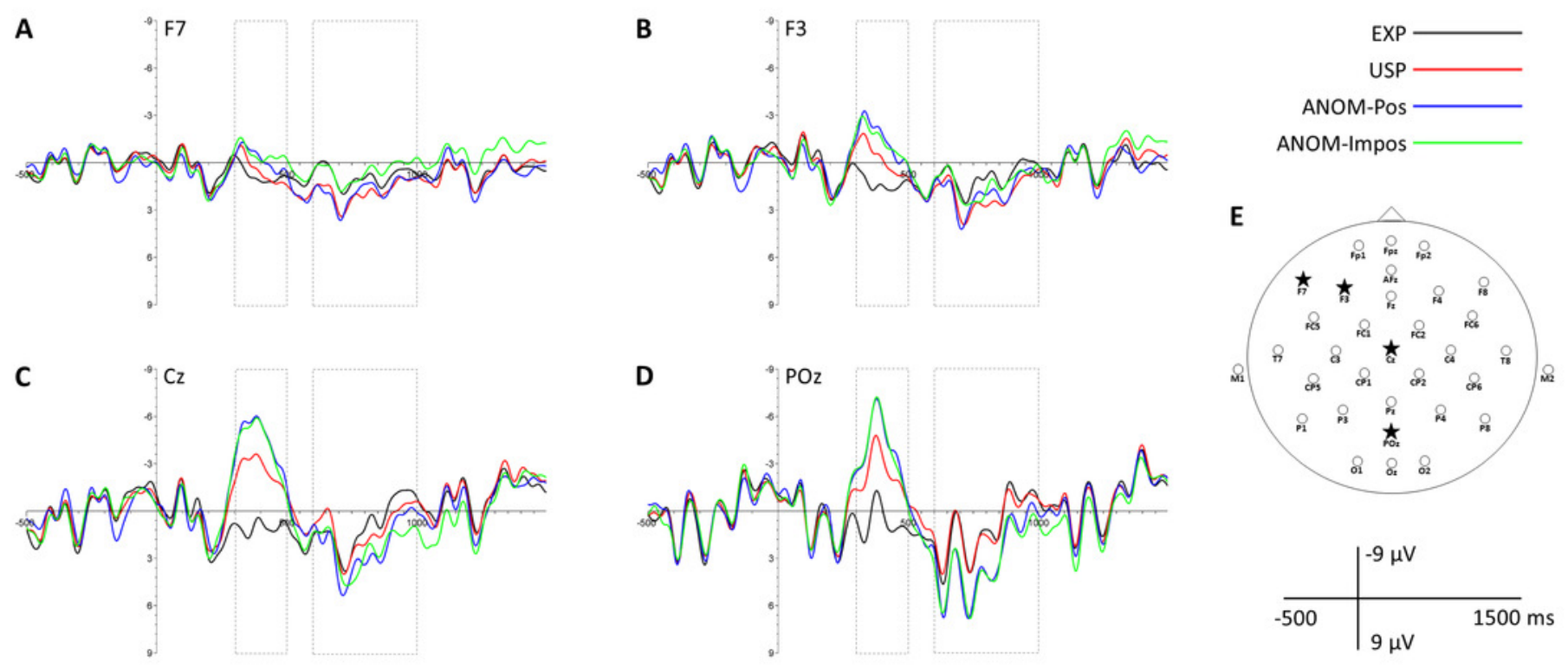


\section{Figure 2}

Mass univariate analyses.

Raster plots of t-values with control for false discovery rates in two dimensional grids of the following comparisons: (A) USP nouns minus EXP nouns, (B) ANOM nouns minus EXP nouns, and (C) ANOM nouns minus USP nouns. Results are plotted in 4 ms lags. Left scalp electrodes are displayed in the upper section, midline scalp electrodes in the center, and right scalp electrodes in the lower section of each panel. Red (blue) indicates that ERPs to the first noun type are more positive (negative) than ERPs to the second noun type. See Fig. 1E for electrode placement. 


\section{A USP - EXP}

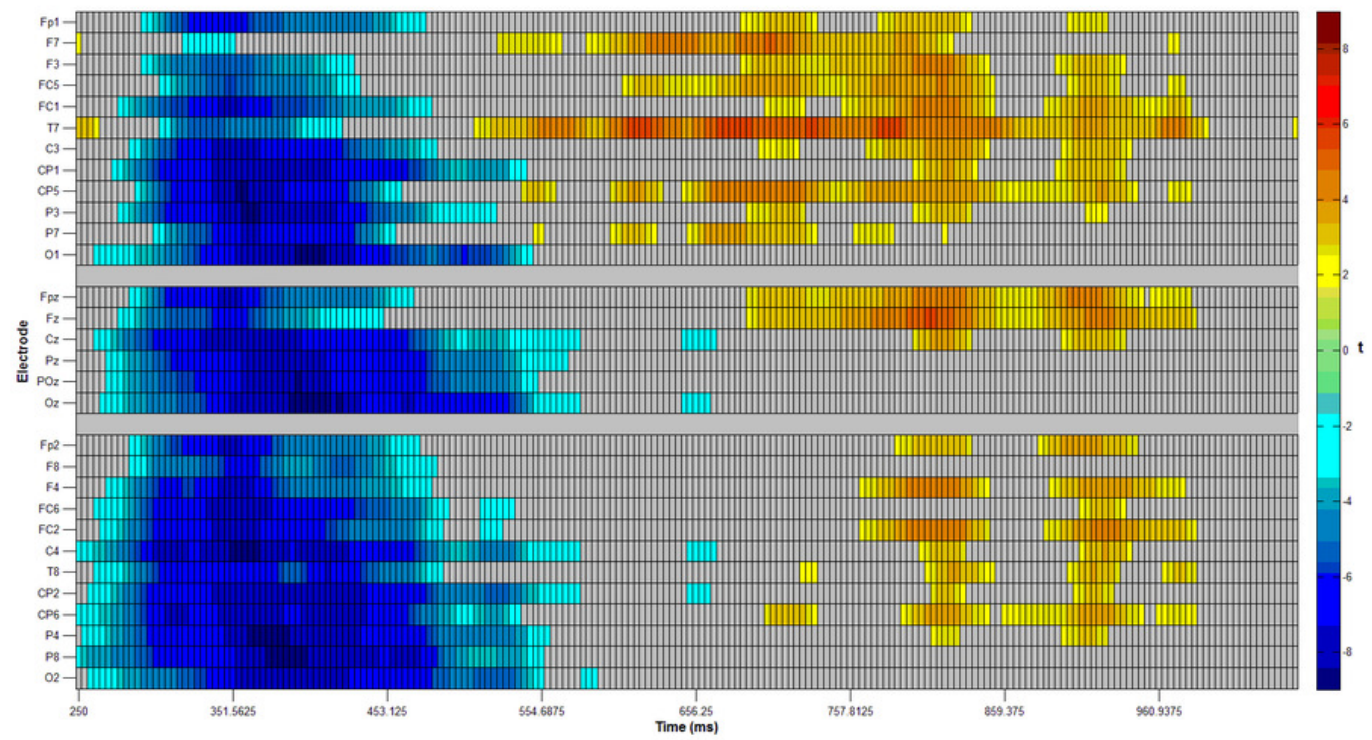

\section{B ANOM - EXP}

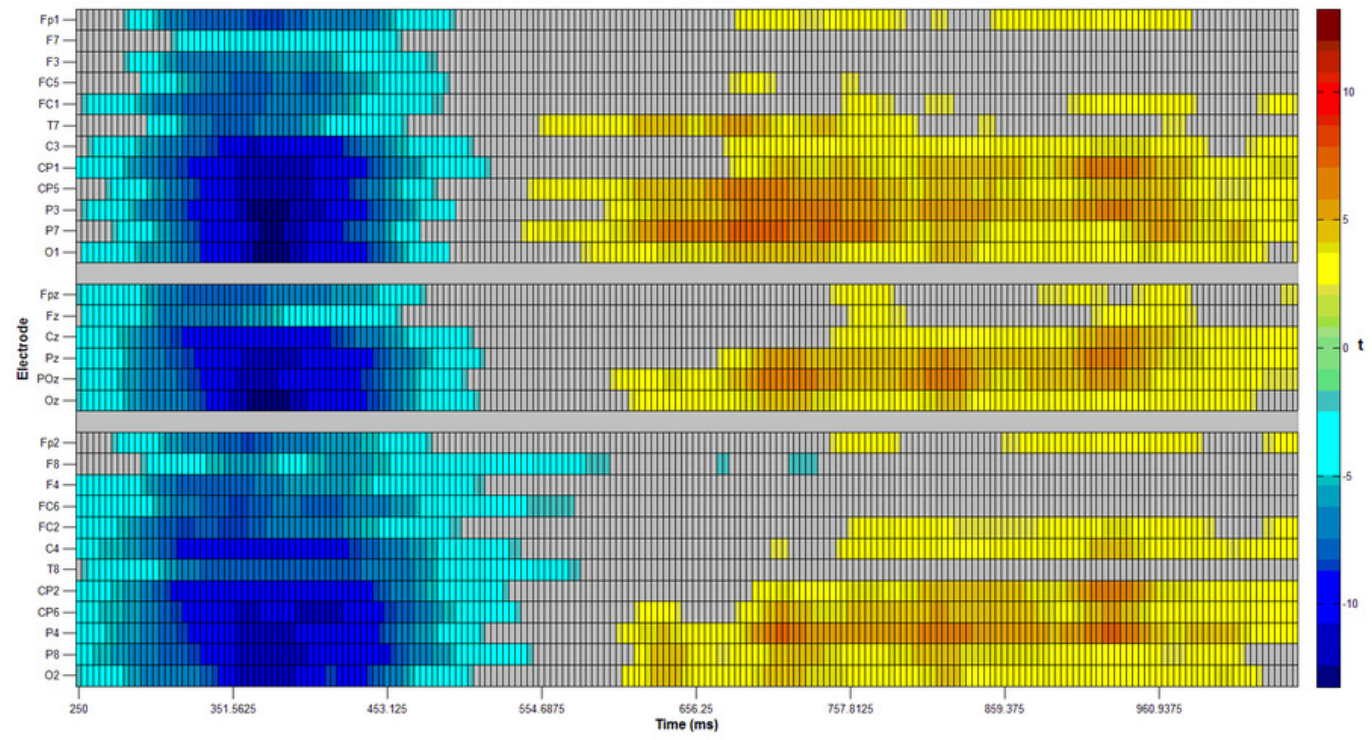

C ANOM-USP

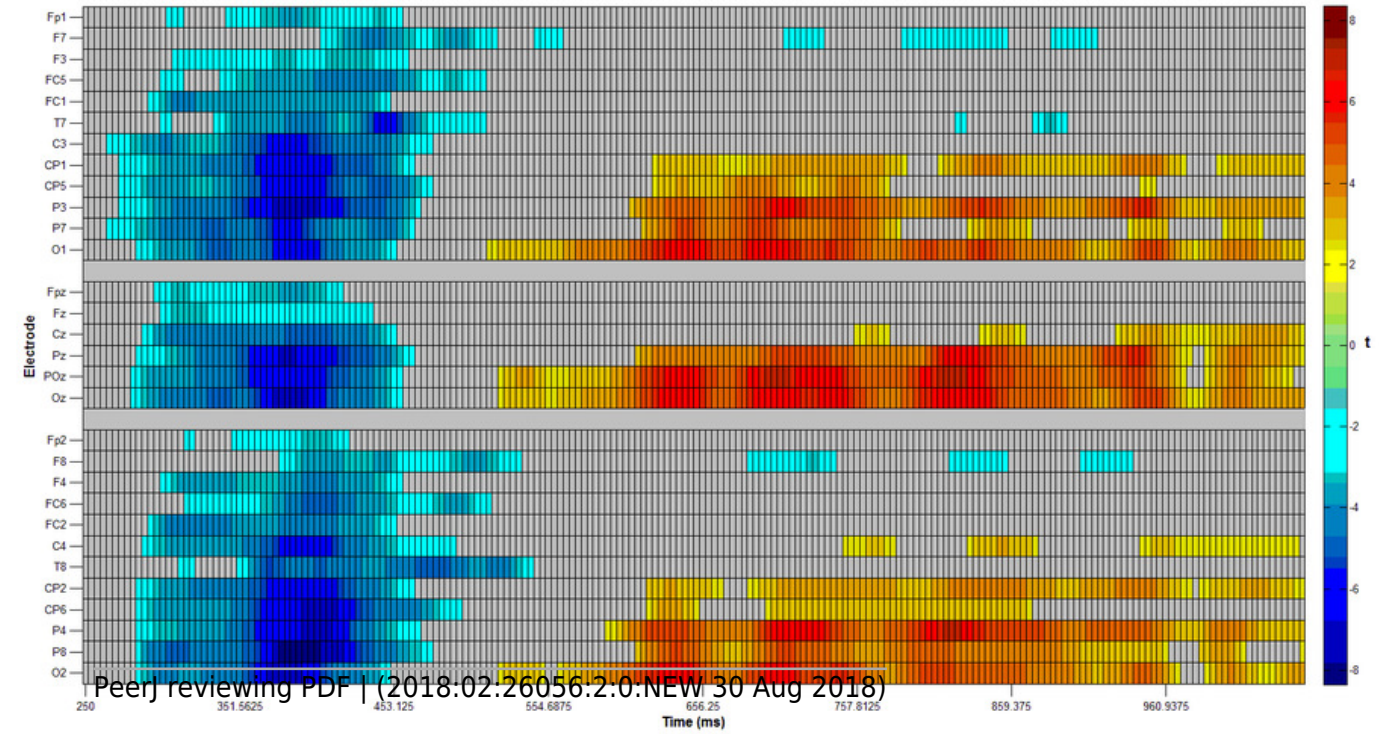


Figure 3

Grand average $(n=32)$ recorded over 30 scalp channels.

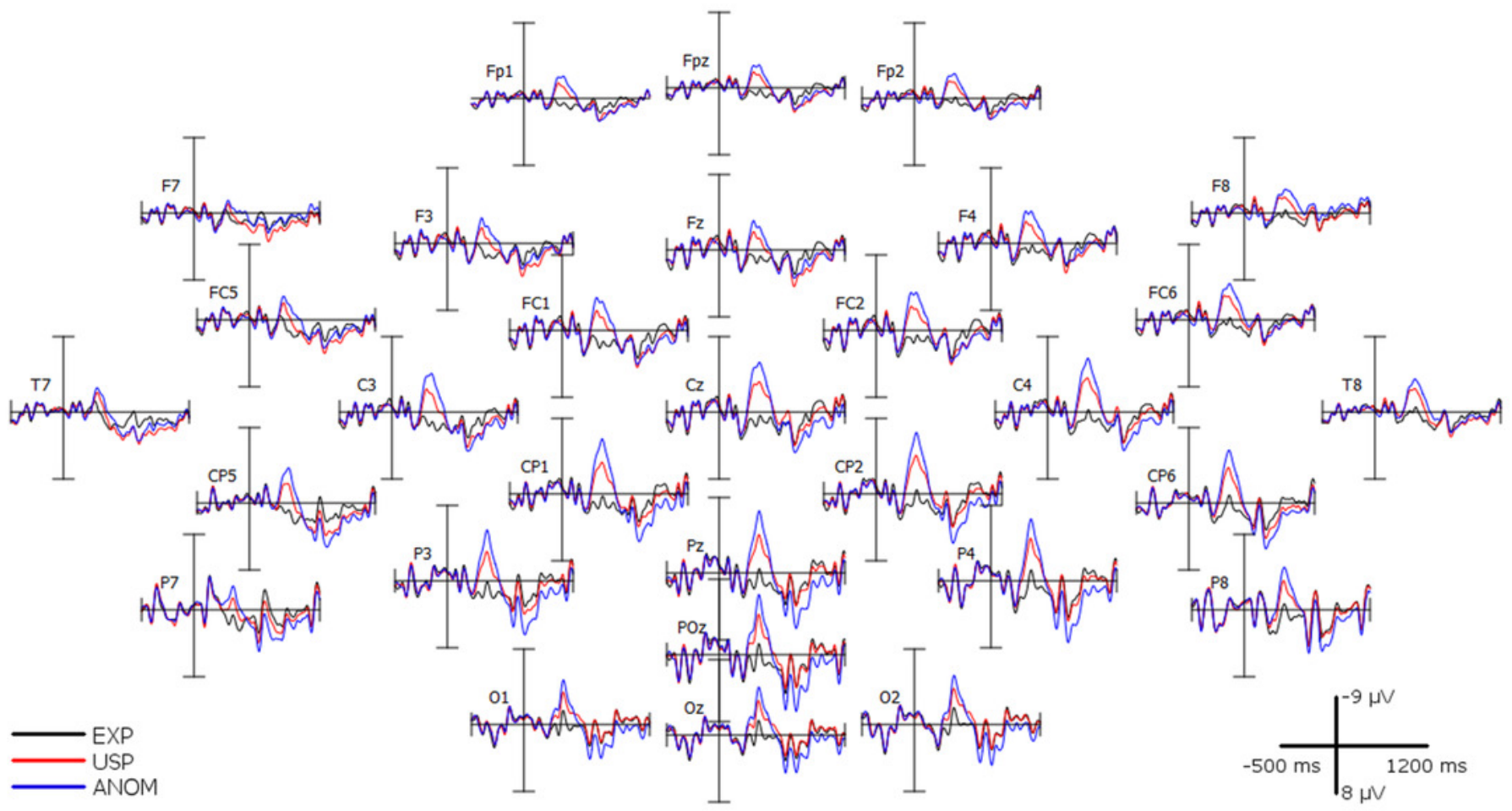


Figure 4

Topographic scalp maps.

ERP mean voltage differences of the three main comparisons for time points 300 to $1100 \mathrm{~ms}$.

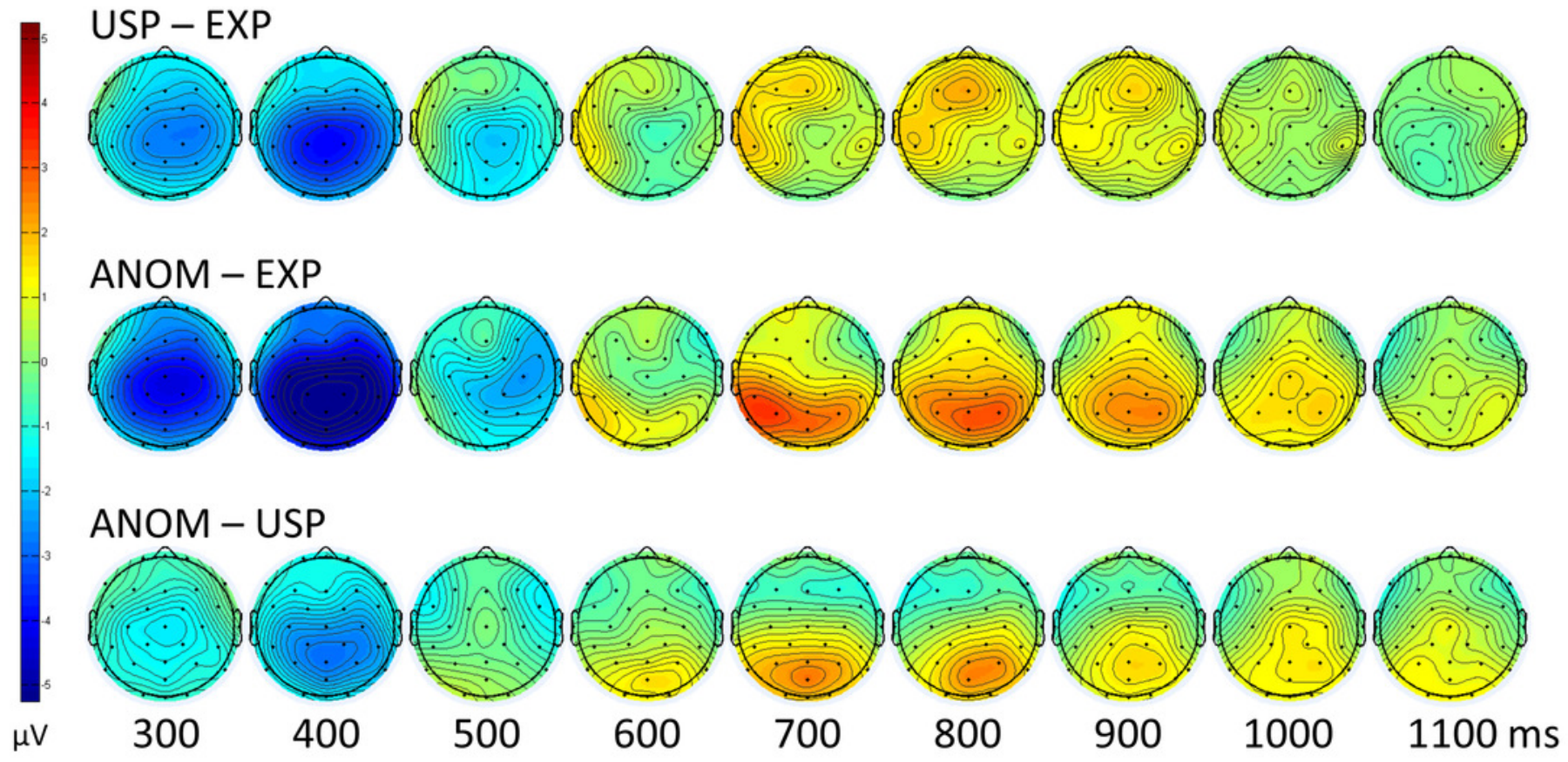


Figure 5

Comparison of results

EEG results from the current study $(A-C)$ and Experiment 2 by DeLong, Quante, and Kutas (2014) (D-F), for three time windows (N400, Anterior Positivity, Posterior Positivity) and three noun conditions (EXP, USP, ANOM). Significance levels of pairwise t-tests were Bonferroniadjusted $\left(\mathrm{p}_{\text {boncor }}<.0167\right)$.
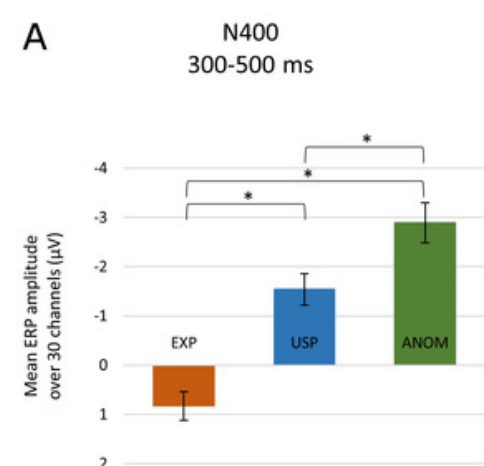

D

$$
\begin{aligned}
& \mathrm{N} 400 \\
& 300-500 \mathrm{~ms}
\end{aligned}
$$

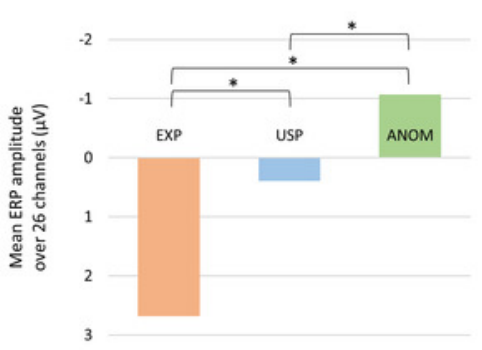

B Anterior Positivity 600-1000 ms

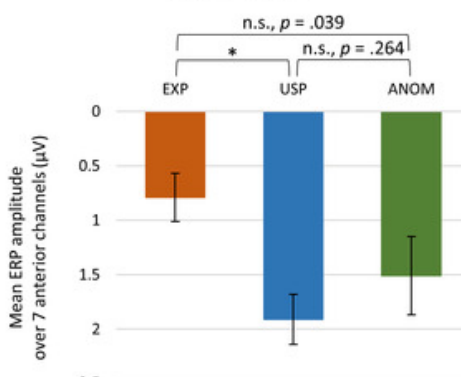

2.5

E Anterior Positivity
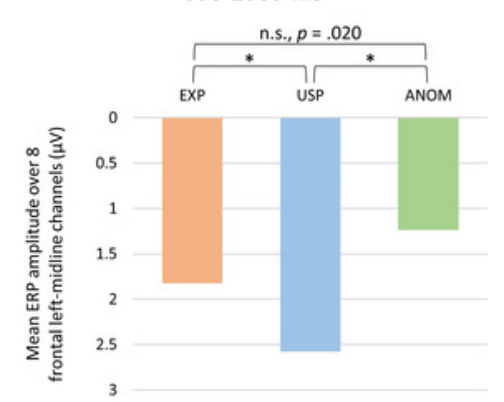

C Posterior Positivity

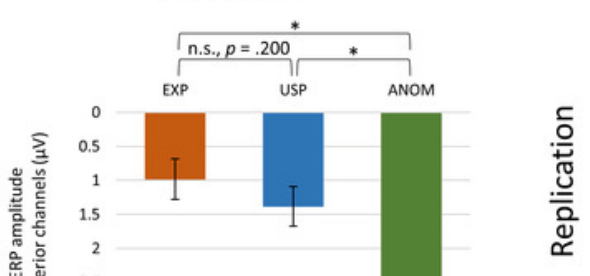

F Posterior Positivity 600-1000 ms

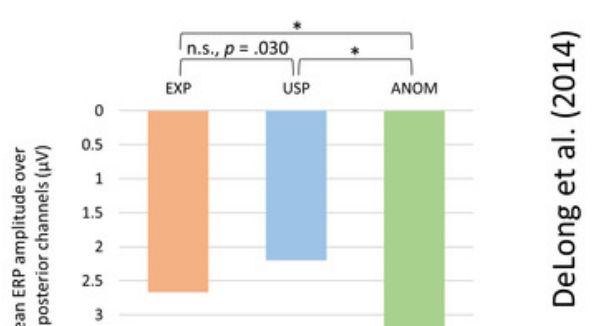




\section{Table $\mathbf{1}$ (on next page)}

Sample sentence pairs 


\section{EXP, USP, ANOM-Impos}

1. Peter stand bei Morgendämmerung auf, fuhr den ganzen Tag Traktor und fütterte abends seine Kühe. An manchen Tagen wäre er aber lieber kein [Bauer, Erwachsener, Trick] sondern ein unbekümmertes Kind. (Peter gets up at dawn, drives the tractor all day and feeds his cows in the evening. On some days he would rather not be a [farmer, adult, trick] but a carefree child.)

\section{Comprehension question: Does Peter have cows?}

2. Alice brach sich ihr Bein im Wanderurlaub. Der Arzt röntge ihr Bein und legte es in einen [Gips, Rollstuhl, Vogel] für zehn Wochen. (Alice broke her leg while hiking. The doctor x-rayed her leg and put it in a [cast, wheelchair, bird] for ten weeks.)

3. Anne schrieb gerade ihre Masterarbeit und brauchte noch weitere Quellen für ihre Annahmen. Deshalb machte sie sich auf den Weg in eine [Bibliothek, Lehrbuchsammlung, Feder] für ihren Fachbereich. (Anne was writing her master's thesis and needed more sources for her assumptions. Therefore, she made her way to a [library, textbook collection, feather] for her department.)

\section{EXP, USP, ANOM-POS}

4. Luisas neues WG-Zimmer war sehr klein, hatte aber hohe Decken. Um Platz zu sparen, kaufte sie sich deshalb ein [Hochbett, Aufbewahrungssystem, Schwein] im Baumarkt. (Luisa's new room was very small but had high ceiling. To save space, she bought herself a [loft bed, storage system, pig] in the store.)

Comprehension question: Was Luisa's new room very small?

5. Frank hält sich selbst für einen Komiker. Trotzdem kennt er nicht einen [Witz, Schauspieler, Anzug] oder Sketch, über den sein Publikum lachen würde. (Frank considers himself quite a comedian. But he doesn't know a [joke, actor, suit] or sketch his audience would laugh about.)

6. Marleen war schüchtern und konnte nicht gut mit Lob umgehen. Sie war peinlich berührt durch ein [Kompliment, Tattoo, Bügeleisen] ihres Vorgesetzten. (Marleen was very shy and could not handle praise well. She was embarrassed by a [compliment, tattoo, iron] from her supervisor.)

FILL

7. Marina war viel auf Reisen und erlebte fast jeden Tag etwas Neues. Um sich an alles zu erinnern, schrieb sie ein [Tagebuch] und klebte Fotos dazu. (Marina travels a lot and has new experiences almost every day. To remember everything, she writes a [diary] and adds pictures.) 
Table 2 (on next page)

Stimuli characteristics 


\begin{tabular}{|c|c|c|c|c|c|c|c|c|c|}
\hline $\begin{array}{l}\text { Condition } \\
\text { label }\end{array}$ & Condition & $\begin{array}{l}\text { Number } \\
\text { of items }\end{array}$ & $\begin{array}{c}\text { Mean critical } \\
\text { noun cloze } \\
\text { probability } \\
\text { (SD), Range: } \\
0-1\end{array}$ & $\begin{array}{c}\text { Mean context } \\
+ \text { noun } \\
\text { plausibility } \\
\text { rating (SD), } \\
\text { Range: } 1-5\end{array}$ & $\begin{array}{c}\text { Mean context } \\
+ \text { noun } \\
\text { possibility } \\
\text { rating (SD), } \\
\text { Range: } 1-4\end{array}$ & $\begin{array}{c}\text { Mean } \\
\text { contextual } \\
\text { constraint } \\
\text { (SD), Range: } \\
0-1\end{array}$ & $\begin{array}{l}\text { Mean critical } \\
\text { noun written } \\
\text { frequency } \\
(\text { SD })^{a}\end{array}$ & $\begin{array}{l}\text { Mean critical } \\
\text { noun length } \\
\text { (SD) }\end{array}$ & $\begin{array}{c}\text { Mean critical } \\
\text { orthographic } \\
\text { neighborhood } \\
\text { size }(S D)^{b}\end{array}$ \\
\hline EXPected & $\begin{array}{c}\text { High } \\
\text { cloze/High } \\
\text { plausibility }\end{array}$ & 150 & $0.77(0.14)$ & $4.68(0.36)$ & $3.77(0.33)$ & $0.77(0.14)$ & $\begin{array}{c}2148.27 \\
(4233.85)\end{array}$ & $6.91(2.55)$ & 11.99 (16.08) \\
\hline $\begin{array}{l}\text { Unexpected } \\
\text { Somewhat } \\
\text { Plausible } \\
\text { (USP) }\end{array}$ & $\begin{array}{c}\text { Low } \\
\text { cloze/High } \\
\text { plausibility }\end{array}$ & 150 & $<0.01(<0.01)$ & $2.96(0.99)$ & $3.19(0.56)$ & $0.77(0.14)$ & $\begin{array}{c}2551.02 \\
(5749.39)\end{array}$ & $7.38(3.15)$ & $12.76(17.99)$ \\
\hline ANOMalous & $\begin{array}{l}\text { Low } \\
\text { cloze/Low } \\
\text { plausibility }\end{array}$ & 150 & $<0.01(<0.01)$ & $1.05(0.13)$ & $1.44(0.45)$ & $0.77(0.14)$ & $\begin{array}{c}2278.32 \\
(4278.45)\end{array}$ & $6.95(2.75)$ & $12.89(18.00)$ \\
\hline$-\frac{\text { ANOM- }}{\text { Impos }}$ & $\begin{array}{c}\text { ANOM + } \\
\text { impossible } \\
\text { meaning }\end{array}$ & 105 & $<0.01(<0.01)$ & $1.02(0.11)$ & $1.20(0.18)$ & $0.77(0.14)$ & $\begin{array}{c}2659.35 \\
(4840.02)\end{array}$ & $6.57(2.45)$ & $14.89(19.81)$ \\
\hline$-\frac{\text { ANOM- }}{\text { Pos }}$ & $\begin{array}{l}\text { ANOM + } \\
\text { possible } \\
\text { meaning }\end{array}$ & 45 & $<0.01(<0.01)$ & $1.11(0.14)$ & $2.00(0.38)$ & $0.78(0.14)$ & $\begin{array}{c}1369.05 \\
(2268.36)\end{array}$ & $7.84(3.02)$ & $8.14(11.53)$ \\
\hline$\underline{\text { FILL }}$ & $\begin{array}{c}\text { High } \\
\text { cloze/High } \\
\text { plausibility }\end{array}$ & 50 & $0.76(0.18)$ & - & - & $0.76(0.18)$ & $\begin{array}{c}3276.12 \\
(5290.63)\end{array}$ & $7.20(2.86)$ & $9.62(11.36)$ \\
\hline
\end{tabular}

b Orthographic neighborhood size (as defined by Coltheart, Davelaar, Jonasson, \& Besner, 1977) according to dlexDB 


\section{Table $\mathbf{3}$ (on next page)}

Differences between conditions 


\begin{tabular}{ccccccc}
\hline Comparison & Plausibility & Possibility & $\begin{array}{c}\text { Word } \\
\text { frequency }\end{array}$ & $\begin{array}{c}\text { Orthographic } \\
\text { neighbors }\end{array}$ & Word length & $\begin{array}{c}\text { Contextual } \\
\text { constraint }\end{array}$ \\
\hline EXP vs. & $t(298)=$ & $t(298)=$ & $t(298)=$ & $t(298)=$ & $t(298)=$ & - \\
USP & 19.89, & 10.81, & -0.63, & -0.30, & -1.43, & - \\
& $\boldsymbol{p}<.001$ & $\boldsymbol{p}<.001$ & $p=.528$ & $p=.765$ & $p=.154$ & \\
EXP vs. & $t(298)=$ & $t(298)=$ & $t(298)=$ & $t(298)=$ & $t(298)=$ & - \\
ANOM & 116.21, & 51.10, & -0.26, & -0.45, & -0.15, & - \\
& $\boldsymbol{p}<.001$ & $\boldsymbol{p}<.001$ & $p=.792$ & $p=.650$ & $p=.879$ & \\
USP vs. & $t(298)=$ & $t(298)=$ & $t(298)=$ & $t(298)=$ & $t(298)=$ & - \\
ANOM & 23.47, & 29.96, & 0.41, & -0.15, & 1.25, & \\
ANOM-Pos & $\boldsymbol{p}<.001$ & $\boldsymbol{p}<.001$ & $p=.684$ & $p=.882$ & $p=.213$ & \\
vs. ANOM- & $t(67.58)=$ & $t(53.11)=$ & $t(145.15)=$ & $t(131.79)=$ & $t(67.00)=$ & $t(85.06)=$ \\
Impos & $\mathbf{p}<.88$, & 13.62, & -2.21, & 2.60, & 2.38, & 0.34, \\
\hline Ben & $\boldsymbol{p}<.001$ & $\boldsymbol{p}=.028$ & $\boldsymbol{p}=.011$ & $\boldsymbol{p}=.020$ & $p=.738$ \\
\hline
\end{tabular}

Because of unequal group sizes, a Welch-test was conducted in case of ANOM-Pos vs. ANOM-Impos.

Significant $p$-values are marked in bold. 


\section{Table 4 (on next page)}

Mean amplitude and standard deviation $(\mu \mathrm{V})$ of the four noun types across time windows and different scalp sites 


\begin{tabular}{cccccc}
\hline & EXP & USP & ANOM & ANOM-Pos & ANOM-Impos \\
\hline N400 & $0.83(1.63)$ & $-1.54(1.82)$ & $-2.89(2.32)$ & $-3.01(2.41)$ & $-2.82(2.43)$ \\
Anterior Positivity & $0.79(1.24)$ & $1.91(1.32)$ & $1.51(2.05)$ & $1.96(2.19)$ & $1.33(2.27)$ \\
Posterior Positivity & $0.98(1.68)$ & $1.38(1.66)$ & $3.09(2.32)$ & $2.95(2.42)$ & $3.16(2.46)$ \\
\hline
\end{tabular}

1 


\section{Table 5(on next page)}

Pairwise t-tests between the four noun types 


\begin{tabular}{|c|c|c|c|c|}
\hline & $\begin{array}{c}\text { Mean of the } \\
\text { differences }[\mu \mathrm{V}]\end{array}$ & $t(31)$ & $p$ & $\begin{array}{c}95 \% \text { confidence } \\
\text { interval }\end{array}$ \\
\hline \multicolumn{5}{|c|}{$300-500 \mathrm{~ms}$, all scalp sites (N400) } \\
\hline EXP vs. USP & 2.37 & 8.48 & $<.001^{*}$ & {$[1.80 ; 2.94]$} \\
\hline EXP vs. ANOMI & 3.65 & 9.26 & $<.001^{*}$ & {$[2.85 ; 4.46]$} \\
\hline EXP vs. ANOMP & 3.84 & 9.83 & $<.001 *$ & {$[3.04 ; 4.64]$} \\
\hline USP vs. ANOMI & 1.28 & 4.38 & $<.001^{*}$ & {$[0.68 ; 1.88]$} \\
\hline USP vs. ANOMP & 1.47 & 5.83 & $<.001 *$ & {$[0.95 ; 1.98]$} \\
\hline ANOMP vs. ANOMI & -0.19 & -0.72 & .479 & {$[-0.72 ; 0.35]$} \\
\hline \multicolumn{5}{|c|}{$600-1000 \mathrm{~ms}$, posterior scalp sites } \\
\hline EXP vs. USP & -0.40 & -1.31 & .200 & {$[-1.02 ; 0.22]$} \\
\hline EXP vs. ANOMI & -2.17 & -5.40 & $<.001^{*}$ & {$[-2.99 ;-1.35]$} \\
\hline EXP vs. ANOMP & -1.97 & -4.29 & $<.001^{*}$ & {$[-2.90 ;-1.03]$} \\
\hline USP vs. ANOMI & -1.77 & -4.87 & $<.001^{*}$ & {$[-2.52 ;-1.03]$} \\
\hline USP vs. ANOMP & -1.57 & -4.75 & $<.001^{*}$ & {$[-2.24 ;-0.89]$} \\
\hline ANOMP vs. ANOMI & -0.21 & -0.72 & .477 & {$[-0.80 ; 0.38]$} \\
\hline \multicolumn{5}{|c|}{$600-1000 \mathrm{~ms}$, anterior scalp sites } \\
\hline EXP vs. USP & -1.12 & -3.97 & $<.001 *$ & {$[-1.70 ;-0.55]$} \\
\hline EXP vs. ANOMI & -0.54 & -1.52 & .138 & {$[-1.27 ; 0.18]$} \\
\hline EXP vs. ANOMP & -1.17 & -2.88 & $.007^{*}$ & {$[-2.00 ;-0.34]$} \\
\hline USP vs. ANOMI & 0.58 & 1.50 & .145 & {$[-0.21 ; 1.37]$} \\
\hline USP vs. ANOMP & -0.05 & -0.12 & .904 & {$[-0.84 ; 0.74]$} \\
\hline ANOMP vs. ANOMI & 0.63 & 1.89 & .068 & {$[-0.05 ; 1.31]$} \\
\hline
\end{tabular}

* Significant after Bonferroni adjustment $\left(p_{\text {boncor }}<.0083\right)$ 